\title{
Bookreview
}

David L. Hawksivorth and Davio J. HILI

\section{THE LICHEN-FORMING FUNGI}

Tortiary Lovel Biology Series; Blackie and Son Ltd., Glasgow and London 1985, 158 pp., 56 Figs. 25 Tables, Price $7.95 £(16.95 £$ cased $)$.

Intensive study of lichens has lately brought advances in knowledge, which have considerably changed some ideas of the biology and taxonomy of these interesting organisms. Lichens are not taken as a separate natural group, but from the point of viow of phylogeny are considered one strategy of fungi roalising their nutrition by symbiosis with a photosynthetic partner. The authors accepted this conception and they wrote in a their preface: "While this book can also be) employed as the besis of special courses devoted to lichens, it is our primary intention that it will be utilized much more widely and contribute to the integration of lichenology in mainstream biology teaching. This is long overdue, but we are confident that teachers and lecturers will find it a mutually boneficial symbiosis."

The presented book is a textbook, therefore the authora have emphesized topica of particular interest from many aspects of lichenology to advanced undergraduate and postgraduate biologists. Examples for illustration are drawn mainly from Europe.

The opening chapter is important and submits an original view on deliminating lichens with examples of various biological relations in fungus-alge associations, three- and four-membered symbioses and systematic positions of mycobionts (fungal partners) and photobionts (photosynthetic partners, which may be either phycobionts, i.e. green algae, or cyanobionts, i.e. cyanobacteria, formerly referred to as blue-green algae). The chapters dealing with thallus structure and reproduction incorporate the latest results (study of ascomata ontogeny, ascus types, conidiomata) and bring an outline of evolutionary trends in reproductive strategies. The establishment phase of lichen thalli and physiological responses to different environmental factors are reviewed in two chapters. Aspects of ecology (the interactions of lichens with substratum factors) and sociology (interactions of individuals among themselves and development of communities) slong with interactions with other organisms form the contents of the following chapter. Biogeography has made progress in particular regions and groups of lichens during the last 15 years. It is mentioned to illustrate patterns of distribution and the effects of man (elimination as well as extension and introduction). Another part of lichenology is still progressing: the chemistry of lichen compounds, therefore a special chapter is devoted to secondary metabolites, their biosynthetic routes, microchemical determination and location in lichens. In addition, the systematic value and role of lichen products are discussed. The last chapter covers the main topic, which is bound up with lichens at present: environmental monitoring. Selected aspects are drawn from a vest literature to demonstrate lichen bioindication (scales, content of heavy metals and radionuclides). The use of lichens as monitoring organiams is not confined only to air pollution; other factors are monitored as well (e.g. ecological continuity of woodlands or dating of substratum exposure). References (including comprehensive reviews) for further reading are arranged according to the chapters of the book.

All parts of the book are proportionally compiled. In spite of its rather small volume the book covers a great extent of lichenology, gives a representative picture of many topics and is aupplemented with valuable recent and often original data. All this makes The Lichen-Forming Fungi a useful and valuable book not only for students and teachers. 